rational and in keeping with the principles of the S.I. system.

Whatever decisions are taken by the international bodies concerned, they must find willing acceptance by national professional bodies and, even more important, by the individual physicians who will be directly affected in practice. In some countries haemoglobinometry is performed by clinical chemists in some laboratories and by haematologists in others. The confusion which could follow if different conventions are adopted by the two disciplines is disturbing, and its possibility points to the need for universal agreement on whatever convention is adopted. Any change should be co-ordinated among the different specialties and by all laboratories in each country.

Whatever changes are made will be far-reaching, requiring recalibration of apparatus and new report forms as well as making it necessary for doctors and laboratory technicians to become conversant with an entirely new set of values to replace those with which they are familiar. Such changes should not be undertaken lightly. For this reason the International Committee for Standardization in Hematology is sponsoring a series of discussions at international congresses during the next few months ${ }^{6}$ to ensure that haematologists become conversant with the proposals, and have ample opportunity to be involved with the decisions for change, if indeed change there must be.

1 Dybkaer, R., and Jofgensen, K.,Quantities and Units in Clinical Chemistry Copenhagen, Munskaard, 1967.

Royal College of Pathologists Working Party, fournal of Clinical Pathology $1970,23,818$

Broughton, P. M. G.,Quantities and Units in Clinical Biochemistry, Bulletin No. 20. London, Association of Clinical Biochemists, 1970

- Dybkaer, R., in Standard Methods of Clinical Chemistry, 1970, 6, 223.

5 International Committee for Standardization in Hematology, British, fournal of Haematology, 1967, Supplement 13, 71

6 International Committee for Standardization in Haematology Working Party on Quantities and Units, 1972.

\section{Supersonic Radiation Risks}

Concorde in all its aspects is a recurring theme in public discussion. Its possible effects on the economy, on the environment, and on health are all debated. Among the main problems deserving study are those of noise and radiation.

As we go higher so the shield presented by the atmosphere against galactic and solar radiation decreases. At sea level we have the equivalent of $3 \mathrm{ft}(90 \mathrm{~cm})$ of lead roof over our heads. At the altitudes where subsonic airliners fly, $37,000-40,000 \mathrm{ft}(11,000-12,000 \mathrm{~m})$, it is equivalent to 7 in $(18 \mathrm{~cm})$ of lead, and at supersonic altitudes, 56,000-60,000 $\mathrm{ft}(17,000-18,000 \mathrm{~m})$, about $2 \frac{1}{2}$ in of lead. The steady-state radiation burden of free space is about 17 mrems per day, 12 and reviews ${ }^{3-5}$ have indicated that about 0.6-1 mrem per hour is a representative dose for passengers at $58,000 \mathrm{ft}(17,500 \mathrm{~m})$ and fairly high latitudes. F. J. Ensell ${ }^{6}$ has already reported that these estimates are in fact being confirmed. These doses must be considered in comparison with a background dose of 120 mrems per year in London, about 300 mrems in Aberdeen, and 2,000 mrems in Kerala State in India, as well as other sources of radiation in our modern life. A person very close to a colour television set is subjected to 0.5 mrems per hour. A mass miniature radiography chest $x$-ray examination on an old set may give 10 mrems, and other medical procedures make considerable additions to our personal totals of radiation.

For the average passenger, therefore, a three-hour trip in a Concorde seems relatively harmless, but the snag is that solar flares do occur, though relaitively rarely. ${ }^{7}$ During a flare the radiation dose at a cruising level of about $56,000 \mathrm{ft}$ $(17,000 \mathrm{~m})$ rapidly increases. For instance, a flare in 1956 gave a calculated dose rate of about 2 rads per hour at $60,000 \mathrm{ft}(18,000 \mathrm{~m}) .89$

Adequate warning must therefore be available to the aircrew in the event of a solar flare. ${ }^{10}$ Ground-based warnings will not be good enough because of rapid deterioration in telecommunications and therefore the aircraft itself must carry detector equipment. If the detector is unserviceable, the aircraft will not be allowed to operate at altitudes for supersonic cruising. Such equipment ${ }^{11}$ is fitted to the Concordes. Ensell ${ }^{6}$ has indicated that it is returning values close to predicted postulates. If a warning of high-dose radiation becomes operative, the Concorde can descend rapidly to a safe altitude without inconveniencing the passengers.

Provided the detector is operative, the captain takes note of it, and can descend, the risk to patients from radiation is negligible, and doctors can reassure inquirers. Moreover, the chance of a solar flare occurring during an individual journey is statistically very low.

1 Berry, C. A., Aerospace Medicine, 1970, 41, 500.

2 Mandrovsky, B. N., Aerospace Medicine, 1971, 42, 172.

${ }^{3}$ McNaughton, I. I., Royal Aircraft Establishment Technical Report 68286, December 1968

Fuller, E. W., and Day, B., International Congress on Protection against Accelerator and Space Radiation. Geneva, CERN, 1971.

${ }^{5}$ Buley, L. E., Aerospace Medicine, 1969, 40, 1134.

${ }^{6}$ Ensell, F. J., British Medical fournal, 1971, 4, 362.

Report of the I.C.R.P. Task Group on the Biological Effects of High Energy Radiations, Health Physics, 1966, 12, 209.

${ }^{8}$ Davisson, P. J. N., The Cosmic Ray Environment of Supersonic Aircraft (Thesis) Bristol University, 1967

${ }^{9}$ Fuller, E. W., and Clarke, N. T., UKAEA/AWRE Report No. 064/68. London, H.M.S.O., 1968.

10 International Commission for Radiological Protection, Report of Com mittee, I.C.R.P. Publication 9. Oxford, Pergamon Press, 1969.

11 Benbow, T. G., Fifth International Aerospace Instrument Symposium Cranfield, March 1968.

\section{Zoster and Hodgkin's Disease}

Herpes-zoster-varicella infection is commoner in patients with malignant disease than in the general population. The increase in incidence is particularly great in patients with Hodgkin's disease. ${ }^{1-3}$ Recurrent exacerbations may occur and the infections may become disseminated and cause death.

In a series of 592 patients with Hodgkin's disease at Stanford Medical Centre 91 (15.4\%) had zoster infections at some time during the course of their diseases. ${ }^{4}$ An even higher incidence $(25 \%)$ was reported over a 24 -month period in 102 patients with Hodgkin's disease attending the Baltimore Cancer Research Centre. ${ }^{5}$ The incidence of this infection among patients in both centres with lymphomas other than Hodgkin's disease was less ( $7 \cdot 1$ and $8.7 \%$ ). The infection is not so common in patients with other forms of malignant disease, including solid tumours and acute leukaemia, though it appears to be rather commoner than in the general population. Impairment of the patient's resistance by other disease, splenectomy, radiotherapy, and chemotherapy all predispose to infection. The defect in cellular immunity characteristic of Hodgkin's disease is thought to predispose especially to the development of this 
virus infection. ${ }^{6}$ Delayed hypersensitivity skin responses were measured in 59 patients with Hodgkin's disease in the Baltimore series, and the incidence of infection was greater in the non-reactors than the reactors (46\% compared with $8.6 \%$ ).

Though antibody may play a part in resistance to infection, it is not the only factor. During an epidemic of zoster infection in Baltimore an absence of antibody in the serum of patients with Hodgkin's disease was associated with a higher risk of infection than in those with antibody, but the incidence was very low in a comparable series of patients without Hodgkin's disease and without detectable antibody. Deficiency in other host resistance factors may also play a part, and there is a suggestion that production of interferon may be impaired in patients with disseminated disease. ${ }^{7}$ The infection is more common in patients with generalized than local Hodgkin's disease, and all but one of the 21 cases of disseminated infection in the Stanford series had stage III or IV disease; $70 \%$ of their series were stage III or IV before development of zoster. They noticed that the incidence of infection was greatest in the last two years of the study, and 50 of the 91 cases of zoster occurred in this period. It was at this time that splenectomy became a routine treatment for their patients, and an analysis showed that $22 \%$ of 150 patients with splenectomy developed zoster compared with $13 \cdot 1 \%$ of 442 who retained their spleens. The incidence of infection was greatest within the first 12 months after splenectomy. Several series have shown that localized zoster usually occurs either at irradiated sites or at sites of the disease. ${ }^{3}$ Using better methods of detecting diseased lymph nodes, workers at both Stanford and Baltimore confirmed this finding. In both series infection usually occurred in the first few months after radiotherapy, and tended to affect the irradiated dermatomes. There is no evidence that this complication altered the prognosis, but disseminated infection is associated with a bad prognosis in most series. ${ }^{8}$ If infection occurred in an unirradiated dermatome, recurrence was expected within the year. Occasionally long remissions have been precipitated by severe zoster-varicella infection.

Evidence that intensive combination chemotherapy has increased the incidence of this infection in patients with Hodgkin's disease is of doubtful validity. A combination of advanced stage, anergy, and recent radiotherapy all predispose to infection with zoster, and it is not clear whether chemotherapy adds to this effect, but immunosuppressive therapy has led to activation of the infection in other patients. ${ }^{9}$ In the Baltimore series many of the patients with solid tumours and leukaemia were receiving intensive chemotherapy, but the incidence of infection was low.

It is generally thought that localized zoster infection is a reactivation of a latent virus that remained dormant in the dorsal root ganglia after chickenpox, but there are a few reports suggesting that zoster can be acquired by reinfection. ${ }^{1011}$ An epidemic was observed in the Baltimore series. In April and early May 1970, 91 patients were exposed to varicella or zoster, and $26 \%$ of the 19 exposed patients with Hodgkin's disease developed zoster, whereas only $2.5 \%$ of the 25 exposed patients with solid tumours became infected. This suggests that prophylactic avoidance of contact with infection by susceptible patients may be of importance. There is some evidence that chickenpox can be prevented in children by giving zoster immune globulin. ${ }^{12}$ Hyperimmune globulin was used during the Baltimore epidemic, but the numbers of patients were too small to assess its value. Hyperimmune gamma globulin, cytosine arabinoside, and 5 idoxyuridine have all shown some effect against established infection, but most reports lack firm evidence of the effect. ${ }^{31314}$ Cytosine arabinoside administration is often followed by rapid resolution of the infection and may well be helpful in preventing continuing pain. Controlled trials are required to assess the value of hyperimmune globulin and chemotherapy in this infection, which can cause suffering as well as death in patients on immunosuppressive treatment.

${ }^{1}$ Pancoast, H. K., and Pendergrass, E. P., American fournal of the Medical Sciences, 1924, 168, 326.

Craver, L., and Haagensen, C. D., American fournal of Cancer, 1932, 16, 502.

3 Sokal, J. E., and Firat, D., American fournal of Medicine, 1965, 39, 452.

Goffinet, D. R., Glatstein, E. J., and Merigan, T. C., Annals of Internal Medicine, 1972, 76, 235 .

${ }^{5}$ Schimpff, S., et al., Annals of Internal Medicine, 1972, 76, 241.

6 Aisenberg, A. C., Cancer Research, 1966, 26, 1152.

Armstrong, R. W., Gurwith, M. J., Waddell, D., and Merigan, T. C., New England fournal of Medicine, 1970, 283, 1182.

Merselis, J. G., Kaye, D., and Hook, E. W., Archives of Internal Medicine, 1964, 113, 679

${ }^{9}$ Rifkind, D., Fournal of Laboratory and Clinical Medicine, 1966, 68, 463

Rado, J. P., Tako, J., Geder, L., and Jeney, E., Archives of Interna Medicine, $1965,116,329$.

${ }^{11}$ Berlin, B. S., and Campbell, T., Fournal of the American Medical Asso-

12 Brunell, P. A., Ross, A., Miller, L. H., and Kuo, B., New England fournal of Medicine, 1969, 280, 1191 .

13 Waltuch, G., and Sachs, F., Archives of Internal Medicine, 1968, 121, 458.

14 Calabresi, T., Annals of the New York Academy of Sciences, 1965, 130, 192.

\section{Towards a New Contract}

A year ago $^{1}$ the C.C.H.M.S. Chairman, Dr. C. E. Astley, criticized the consultant contract as being a major cause of dissatisfaction and a hindrance to improving consultants' pay. ${ }^{2}$ Much has been done since then and at this summer's conference (to be reported soon in the Supplement) the hospital representatives were able to see and approve the results of the C.C.H.M.S.'s review of the consultant contract - that for the training grades is still under study.

The new contract (Supplement, p. 39)-taking a leaf from the general practitioner negotiations in $1966^{3}$ and following up the ideas in the hospital doctors' charter ${ }^{4}$-seeks to relate pay more directly to responsibility and workload. Since 1948 successive Governments have added time-consuming responsibilities-rising workload, increasing on-call commitments, more teaching, and proliferating committee work-all within consultants' existing contracts, and this without really adequate pay adjustments. While, as the recent Review Body maintains, many consultants have the opportunity for private practice and some receive distinction awards, there are nevertheless still many (including part-timers) whose income is almost entirely dependent on N.H.S work. The new proposals for a specified basic commitment of a maximum of 10 notional half days a week, with extra reward for additional commitments, and permission for all consultants to engage in private practice are simple. So much so that many doctors will wonder why the changes were not made before. If the Government accepts them they should go a long way to alleviating the real sense of injustice that exists among hospital staff on this question.

Family doctors were in revolt in the early sixties, not just over their pay but because they sensed that they were being exploited to an extent which prejudiced the standard of care of their patients. So it is now with hospital staff, particularly those consultants working in district hospitals. The clear definition of the basic commitment in the new contract of the consultant's various responsibilities means that the 